\title{
Tratamento de resíduos sólidos no município de Bonito, Mato Grosso do Sul, Brasil, correlacionado com dados externos
}

\author{
Treatment of solid waste in the Bonito municipality, Mato Grosso do Sul, Brazil, \\ correlated with external data
}

\section{Tratamiento de residuos sólidos en el municipio de Bonito, Mato Grosso do Sul, Brasil, correlacionado con datos externos}

\author{
Laís Ribeiro Balbueno ${ }^{1}$ \\ Lorene Almeida Tiburtino-Silva² \\ Micaella Lima Nogueira² \\ Josemar de Campos Maciel ${ }^{2}$ \\ Reginaldo Brito da Costa ${ }^{2}$
}

Recebido em: 10/10/2019; revisado e aprovado em: 21/08/2020; aceito em: 16/09/2020

DOI: http://dx.doi.org/10.20435/inter.v22i3.2768

\begin{abstract}
Resumo: A carência dos serviços efetivos de gestão de resíduos sólidos urbanos (RSU) tem provocado impactos negativos nos recursos naturais e nas condições de vida das populações. Ao investigar os impactos ambientais que os RSU ocasionam e a precariedade da disposição atual desses resíduos em diversos municípios, observase a necessidade de buscar novas e suficientes alternativas, para aperfeiçoar a gestão e eficiência e reduzir custos, melhorando a proteção ambiental. O estudo objetivou compreender como se organiza a coleta de resíduos sólidos, de forma geral, no mundo e no Brasil, com um recorte para o município de Bonito-Brasil, com a finalidade de elaborar um diagnóstico local, comparando-o com dados nacionais e internacionais. A metodologia consistiu em duas etapas: i) revisão bibliográfica com as principais informações sobre a gestão dos resíduos sólidos, em que os autores fizeram uma reflexão sobre os modelos de gestão dos resíduos considerados eficazes; ii)aplicação de questionários no ambiente de ferramentas do Google e o software IRaMuTeQ (acrônimo de Interface de R para Análise Multidimensional de Textos e Questionários). Os questionários foram aplicados no município de Bonito, para a caracterização local. Os resultados mostraram que a maioria das pessoas (72\%) destina os resíduos para os pontos de coleta pública comum e $26 \%$ para a coleta seletiva, sendo que a maior parte (53\%) dos voluntários realiza a separação correta dos resíduos. As análises mostram que, apesar de avanços desejáveis, ainda há necessidade de conscientização, informação e divulgação dos programas e iniciativas implantados pela prefeitura, no que se refere às diretrizes, princípios, instrumentos, práticas e modalidades de coleta adotadas. A partir das análises, constatou-se a intenção de praticar o gerenciamento dos resíduos sólidos, por parte dos voluntários.
\end{abstract}

Palavras-chave: gerenciamento de resíduos; IRaMuTeQ; política de resíduos sólidos.

\begin{abstract}
The lack of effective urban solid waste management (MSW) services has caused significant negative impacts on natural resources and the living conditions of populations. When investigating the environmental impacts caused by MSW and the precariousness of the current disposal of these wastes in several Brazilian municipalities, there is a pressing need to seek new and sufficient alternatives, which are necessary, related to the improvement of management and efficiency, concerning cost reduction and consequent environmental protection. This study aimed to describe and interpret how is organized the collection of solid waste in the world and in Brazil, focusing on the municipality of Bonito-Brasil offering a local diagnosis, comparing it with national and international data. The methodology consisted of two steps: i) bibliographic review of relevant information on solid waste management, in which the authors reflect upon waste management models considered effective; ii) the second step consisted of applying questionnaires using Google tools and the IRaMuTeQ (acronym for Interface de R pour les Analyzes Multidimensionnelles de Textes et de Questionnaires) software. The questionnaires were applied in Bonito for local characterization. The results showed that most people (72\%) dispose of the waste to the common public collection points and $26 \%$ to the selective collection. Most of the volunteers (53\%) make the correct separation of the waste. This information shows that despite desirable advances, there is still a need for information and dissemination of programs and initiatives implemented by the city, regarding the guidelines, principles, instruments, practices, and

\footnotetext{
${ }^{1}$ Centro Universitário Internacional (UNINTER), Campo Grande, Mato Grosso do Sul, Brasil.

2 Universidade Católica Dom Bosco (UCDB), Campo Grande, Mato Grosso do Sul, Brasil.
} 
collection modalities adopted. From the focus group analysis of this qualitative and quantitative research, it was noticed that there is intentionality on the part of the volunteers, verified by the speeches and content recorded, for the practice of household solid waste management.

Keywords: waste management; IRaMuTeQ; solid waste policy.

Resumen: La falta de servicios efectivos de gestión de residuos sólidos urbanos (RSU) ha causado importantes impactos negativos en los recursos naturales y las condiciones de vida de las poblaciones. En este contexto, el presente estudio tuvo como objetivo describir e interpretar cómo se organiza la recolección de residuos sólidos en general en el mundo y en Brasil, con un corte para la municipalidad de Bonito-Brasil, con el fin de elaborar un diagnóstico local y reflexionar sobre la gestión de residuos en Brasil y en todo el mundo. La metodología consistió en dos pasos: i) revisión bibliográfica con la información principal sobre gestión de residuos sólidos, en que se realizó una reflexión sobre los modelos de gestión de residuos sólidos; ii) aplicación de cuestionarios con análisis realizados por el software IRaMuTeQ (acrónimo de Interface de R pour les Analyzes Multidimensionnelles de Textes et de Questionnaires) . Los cuestionarios se aplicaron en Bonito para la caracterización local. Los resultados mostraron que la mayoría de las personas (72\%) eliminan los desechos a los puntos de recolección públicos comunes y el 26\% a la recolección selectiva. La mayoría de los voluntarios (53\%) hacen la separación correcta de los desechos. A partir del análisis de los datos de los cuestionários, se notó que existe la buena intención por parte de los voluntarios para la práctica del manejo de residuos sólidos domésticos.

Palabras clave: gestión de residuos; IRaMuTeQ; política de residuos sólidos.

\section{INTRODUÇÃO}

O aumento nas taxas de natalidade, longevidade, índices populacionais e industrialização, aliado à cultura do consumo e acumulação e à falta de conhecimento sobre a limitação dos recursos ambientais, causa uma desenfreada produção de resíduos sólidos, acarretando impactos ambientais que refletem diretamente na qualidade de vida da população. Outro problema é a extração de recursos naturais sem planejamento adequado, que gera um incremento da pressão sobre os custos e sobre os recursos do ambiente. Essa pressão acaba se mantendo, a fim de não comprometer metas, rendimentos e o ciclo do consumo. Para vir de encontro a esse problema, cada nação investiga as melhores formas de resolvê-lo, o que implica otimizar a extração, melhorar práticas de descarte e reaproveitamento de resíduos sólidos. Para isso, é importante conhecer como se caracteriza a produção e a forma de descarte final, geralmente prescritos na lei local.

O Brasil tem como marco regulador a Política Nacional de Resíduos Sólidos (PNRS), Lei n. 12.305/2010, e considera como resíduos sólidos os materiais, substâncias, objetos ou bens descartados nos estados sólido, semissólido ou líquido, cujas particularidades tornem inviável o seu lançamento na rede pública de esgotos ou em corpos da água. O Brasil ainda apresenta, em grande parte, modelos de descarte incorreto, coleta seletiva informal, insuficiência no sistema de coleta pública e a alta produção de lixo nas cidades. Conforme dados da Associação Brasileira de Empresas de Limpeza Pública e Resíduos Especiais [ABRELPE] (2015), apenas 48\% dos municípios possuem aterros sanitários. O gasto atual com a coleta de resíduos passa dos $\mathrm{R} \$$ 15 bilhões anuais. Para que o restante das cidades se adéque ao mínimo que exige a lei, seria preciso um investimento de $\mathrm{R} \$ 11$ bilhões nos próximos anos.

Anualmente, são gerados no Brasil 78,4 milhões de toneladas de resíduos sólidos urbanos (ABRELPE, 2017). Por sua escala continental, o Brasil apresenta grandes diferenças regionais e aumento da produção de resíduos em todas as regiões e estados. O aumento é de $1 \%$, contra o crescimento de 0,75\% da população urbana entre 2016 e 2017. O brasileiro produz $1 \mathrm{~kg}$ de resíduos sólidos por dia, atingindo um total de 214.868 toneladas diárias no país (GOUVEIA, 2012; ABRELPE, 2017). Conforme dito, o destino de pouco mais da metade dos resíduos sólidos 
produzidos pelas cidades brasileiras são os lixões a céu aberto, incoerentemente com o momento de avanços tecnológicos e com o apelo ao desenvolvimento sustentável. O segundo maior destino dos resíduos são aterros sanitários, que, apesar de minimizar os impactos ambientais e ser preferíveis a nenhum tipo de tratamento, não fazem parte dos métodos mais eficientes abordados na perspectiva de uma economia circular e da logística reversa; entretanto esses instrumentos estão previstos em um recente plano de lei (n. 1.230) de Política Nacional de Resíduos Sólidos (PNRS).

Para a coleta de resíduos descartados, existe o plano nacional de resíduos sólidos (Lei n. $12.305 / 10$ ) e, além dele, cada município tem o seu plano de gestão (que segue o nacional), incluindo as regionalizações. Em especial, o município de Bonito tem amplo destaque no país como sendo um dos principais "paraísos ecológicos" e polos para o ecoturismo (ARRUDA; OLIVEIRA; MARIANI, 2014).

Conforme dados do IBGE (2018), a cidade possui uma população estimada de 21.738 habitantes, área de $4.934,414 \mathrm{~km}^{2}$, em sua quase totalidade do bioma Cerrado, e produz uma média de 30 toneladas de resíduos sólidos por dia (BONITO, 2017). Entender como o resíduo é tratado localmente torna-se importante e estratégico, pelo fato de a cidade ser um polo do ecoturismo. Assim, o objetivo deste artigo é avaliar três pontos: (I) analisar a organização de coleta de resíduos sólidos de forma geral no mundo e no Brasil, com um recorte para o município de Bonito, (II) levantar informações do sistema atual da gestão dos resíduos da área analisada e (III) obter as impressões de residentes sobre a gestão dos resíduos sólidos por meio de questionários semidirigidos, em amostra estatisticamente relevante. Este trabalho desenvolveu-se com critérios analíticos, a partir do uso de literatura especializada, e dados obtidos no trabalho com um grupo de voluntários.

\section{METODOLOGIA}

A metodologia da pesquisa partiu de uma investigação em campo, com voluntários de Bonito, Mato Grosso do Sul (MS), Brasil, mediante o uso de questionário semidirigido, mediado pelo Google Forms. Em seguida, fez-se uso de literatura da área de resíduos, para tratar os dados com software específico e proceder a uma análise, segundo categorias elaboradas a partir dos dados. A análise parte dos dados de livros, artigos e relatórios governamentais oficiais, a partir de uma categoria semântica, buscando as palavras-chave: gestão de resíduos sólidos, características gerais de gestão de resíduos sólidos nos continentes, baseados em classificação de renda, custos gerais e alternativas de mitigação. Os termos foram pesquisados nas bases de dados: Google Acadêmico ${ }^{3}$, SciELO ${ }^{4}$ e Scopus ${ }^{5}$, em inglês e em português, e fornecem elementos para caracterizar a forma de gestão dos resíduos.

Além da literatura citada, foram obtidos dados primários, mediante questionários on-line semi dirigidos, mediados pela plataforma do Google Forms. Foram elaboradas oito perguntas, sendo duas fechadas, objetivando a caracterização da amostra; duas abertas, para fins de análise de conteúdo, e cinco de múltipla escolha, para comparação dos dados municipais.

Os critérios de inclusão para a amostra foram pessoas que moram na área urbana da cidade de Bonito, Estado do Mato Grosso do Sul - Brasil, descritas no texto como "voluntários x", com

\footnotetext{
${ }^{3}$ Disponível em: https://scholar.google.com.br/

${ }^{4}$ Disponível em: https://scielo.br

${ }^{5}$ Disponível em: https://scopus.com/home.uri
} 
uma população em meio urbano estimada em $82,5 \%$ da população total do Município (IBGE, 2019). O formulário construído foi viabilizado para os respondentes em um endereço eletrônico durante o período de 1\%/05/2019 até 09/10/2019. Para estabelecer o N amostral, foi utilizada a equação de padrão para calcular o tamanho da amostra, conforme Santos, Rocha e Silva (2015). Em que "p" é a proporção do espaço amostral, "z" é o nível de confiança em 95\%, a letra "e" representa a margem de erro e "N" é o número total da população.

$$
\text { tamanho da amostra }(T A)=\frac{\frac{z^{2} \cdot p(1-p)}{e^{2}}}{1+\left(\frac{z^{2} \cdot p(1-p)}{e^{2} N}\right)}
$$

Considerando que a soma da população do município de Bonito é de aproximadamente 21.738 habitantes, $\mathrm{N}$ será representado por 16.159 (situação domiciliar urbana). Estimou-se o nível de confiança de $95 \%$ ( $z$ - escores 1,96), refletindo a população total, distribuída de forma mais heterogênea. Portanto o índice de variação dos resultados foi de $8 \%$ (e - escores 0,08 ), estabelecendo um tamanho amostral de 150 pessoas para realização da presente pesquisa, o que efetivamente aconteceu.

O primeiro tratamento dos dados consistiu em organizá-los com o uso de instrumentos de tabulação da plataforma Windows, como as planilhas Excel. Isso permitiu a geração de gráficos ilustrativos dos dados, facilitando a etapa de análise comparativa. As respostas obtidas nas questões abertas foram exportadas para planilhas eletrônicas e para o software IRaMuTeQ (Interface de R pour les Analyses Multidimensionnelles de Textes et de Questionnaires), para a análise de conteúdo.

O software IRaMuTeQ possibilitou processar conteúdos e criar categorias estatísticas para os textos elaborados, por ser uma ferramenta gratuita, ancorada no software $R$ e na linguagem de programação python (KAMl et al., 2016). O IRaMuTeQ viabiliza cinco tipos de tratamentos dos dados: estatísticas textuais clássicas; pesquisa de personalidades de grupos; categorização hierárquica descendente; análises de similitude e nuvem de palavras (SOUZA et al., 2018).

Para análises dos conteúdos textuais, foram utilizadas as técnicas de classificação hierárquica descendente, análise de similitude e nuvem de palavras, que agrupam e organizam os dados graficamente, de acordo com sua frequência. Estas técnicas permitem a identificação por meio de um arquivo único, devidamente configurado em formato texto (.txt) e denominado Rapport ou corpus e segmentos de texto, que correspondem aos textos originais do questionário encaminhado aos voluntários. Considera-se que as palavras empregadas em contexto similares estão relacionadas a um mesmo mundo lexical. Abrangem-se, desta forma, análises quantitativas de dados textuais, pautadas em múltiplos contextos e segundo classes de conteúdo, baseadas na similaridade de vocabulário (ANDRADE; ANDRADE, 2016).

Após a transcrição e leitura do material arquivado e tratado no âmbito do IRaMuTeQ construiu-se o modelo analítico composto por categorias, que corresponderam às classes de palavras geradas pelo software. Na prática da análise, pode-se estabelecer as categorias antes do trabalho de campo, na fase exploratória da pesquisa, ou a partir da coleta de dados. Nesta pesquisa, optou-se pela utilização das categorias analíticas pós-coleta, por serem mais específicas, concretas e por critério lexical. Além disso, elas foram refinadas pelo confronto com diversos 
materiais de campo, que eliminavam o viés da elaboração de hipóteses sem conhecimento de causa ou de contexto. Todos os participantes estavam cientes da pesquisa e colaboraram voluntariamente. A pesquisa seguiu as normas sobre o Termo de Consentimento Livre e Esclarecido, disposto na resolução n. 510/2016 do Conselho Nacional de Saúde.

\section{RESULTADOS E DISCUSSÕES}

\subsection{A gestão dos resíduos sólidos}

A coleta dos resíduos domiciliares e a limpeza de logradouros fazem parte da gestão dos resíduos sólidos, considerada ótima quando a coleta atinge mais de $90 \%$ da população, com frequência de três ou mais vezes por semana. Além disso, elas devem destinar-se a aterros sanitários ou canais de recirculação. Espera-se que a limpeza pública mantenha os espaços em condições de uso, sendo considerada, assim, satisfatória (ANDRADE; FERREIRA, 2011).

Quanto à definição de resíduos sólidos, conforme o parágrafo único do Art. 13 da Lei n. 12.305/10, que institui a Política Nacional de Resíduos Sólidos no Brasil (PNRS), podem ser considerados assim os materiais de descarte gerados em domicílios, da limpeza urbana e nas atividades comerciais ou por prestadores de serviços (exceto serviços de saúde, construção civil e de transportes), caso eles não tenham sido classificados como resíduos perigosos (ANDRADE; FERREIRA, 2011). A partir dos padrões de sustentabilidade, a gestão deve incluir a separação dos resíduos na fonte e, por meio do sistema de coleta seletiva, remeter os resíduos para os locais corretos, tais como os programas de reciclagem e compostagem, além de outras etapas da economia circular (CALDERONI, 2003). No Brasil, entretanto, há obstáculos para uma boa gestão dos resíduos sólidos, como a escassez de recursos e a ausência de priorização para o setor de saneamento. Mesmo em cidades economicamente mais importantes e populosas, notam-se carências e omissões nos sistemas de gestão de resíduos (ANDRADE; FERREIRA, 2011).

No âmbito mundial, interferências de ordem política, técnica e cultural (resultantes principalmente do atual modelo de consumo e da expansiva globalização) agravam a problemática dos resíduos sólidos urbanos (ANDRADE; FERREIRA, 2011). Os gastos com coleta de resíduos sólidos no mundo beiram U\$205,4 bilhões (anuais) e os valores tendem a subir para U\$ 375,5 bilhões em 2025 (YAO et al., 2018).

A gestão dos resíduos apresenta características que variam localmente nas diversas nações do mundo. No entanto encontram-se semelhanças nas modalidades de escolha para o tratamento antes da disposição final, principalmente quanto à classificação de renda. O perfil de classificação de renda sugerida pelo Banco Mundial é lower income (LI), Lower Middle Income (LMI), Upper Middle Income (UMI) e High Income (HIC) (Material Complementar A) (YAO et al., 2018). A compreensão adequada do perfil de uma determinada população, além de informações locais, é importante para implementar planos eficientes de gestão e de políticas públicas (Figura 1). 
Figura 1 - Características na produção de resíduos sólidos, em relação à classificação de renda e os resíduos em diferentes locais do mundo, para o ano de 2018

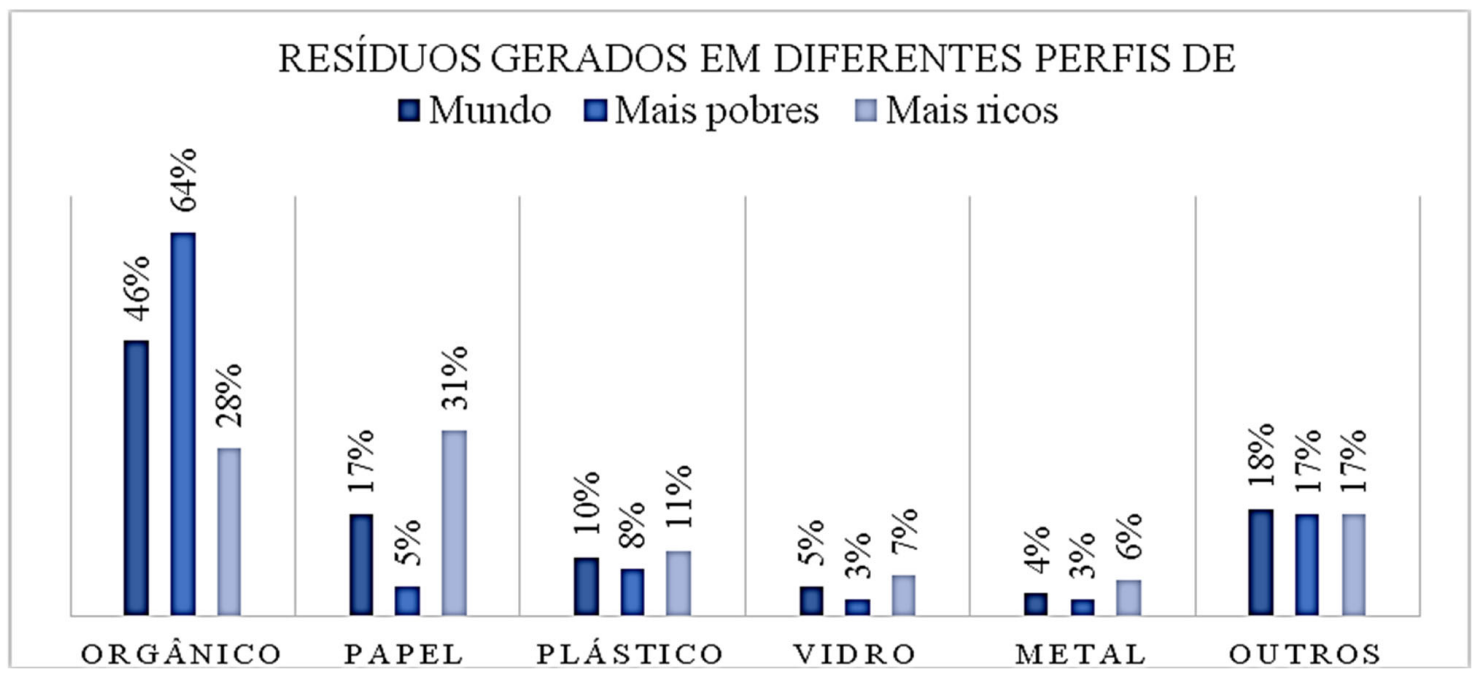

Fonte: Adaptado de Word Bank Group (YAO et al., 2018).

Figura 2 - Geração de resíduos sólidos mundial, de características na produção de resíduos sólidos, em relação à classificação de renda e resíduos em diferentes locais do mundo, para o ano de 2018

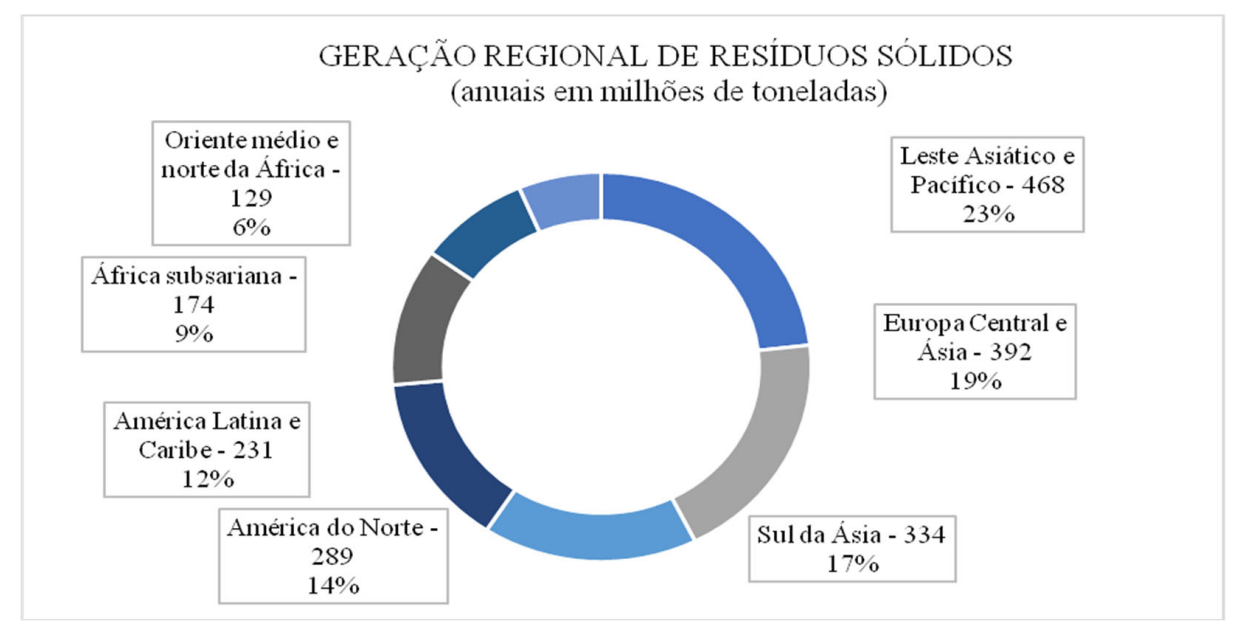

Fonte: Adaptado de Word Bank Group (YAO et al., 2018).

\subsection{Características gerais de gestão de resíduos sólidos em países, em razão da classificação de renda}

Há evidências do World Bank Group (Yao et al., 2018) que mostram os países com menor renda apresentando índices mais altos de reciclagem pelo setor informal (exceto nos resíduos orgânicos) e elevadas taxas de coleta. Países com maior renda gastam menos e possuem sistemas mais eficientes. Portanto é preciso analisar e refletir sobre essas diferenças, para contribuir com uma situação global mais sustentável. O Quadro 1 contém um resumo geral das principais diferenças.

Países integrantes da União Europeia e os Estados Unidos da América apresentam altas taxas anuais de geração de resíduos (MANNARINO; FERREIRA; GANDOLLA, 2016). Ao mesmo 
tempo, apresentam várias estratégias de reciclagem, tratamento e destinação final dos resíduos. Nesse caso, o próprio Estado conduz a separação e destinação final, utilizando Locais de Entrega Voluntária (LEV) ou Pontos de Entrega Voluntária (PEV) e o reúso de recursos como práticas incorporadas pelos cidadãos, o que promove bom desempenho dos sistemas de gerenciamento integrado. Aspectos da economia circular (o conjunto de técnicas de gestão da distribuição e transporte dos produtos, do transporte e manuseio interno às instalações e do transporte das matérias-primas necessárias ao processo produtivo) vêm sendo progressivamente difundidos e incorporados pelas empresas da Europa (NASCIMENTO; CRUZ, 2017; MARCHI, 2011), em que as alterações na gestão de resíduos sólidos urbanos aparecem na legislação local que regulamenta metas para a evolução do setor (MANNARINO; FERREIRA; GANDOLLA, 2016).

Nos Estados Unidos da América, a cidade de San Francisco é um exemplo, pois busca zerar a destinação de resíduos para os aterros sanitários. O governo local promove a educação ambiental, da separação à reciclagem, e o desenvolvimento de novas tecnologias de reaproveitamento. Programas de reciclagem e compostagem de quase todo o resíduo gerado, com incentivos econômicos em consequência destas ações, completam o quadro. A cidade recicla mais de $85 \%$ dos resíduos (SENADO FEDERAL, 2014). 


\begin{tabular}{|c|c|c|c|c|}
\hline \multirow{4}{*}{ 最 } & Atividade & Baixa renda (Low Income) & Renda mediana (Middle Income) & Renda alta (High Income) \\
\hline & $\begin{array}{l}\text { Programas para } \\
\text { redução de } \\
\text { resíduos }\end{array}$ & $\begin{array}{l}\text { Não há programas organizados, porém } \\
\text { existem incentivos para reutilizar e } \\
\text { diminuir resíduos. }\end{array}$ & $\begin{array}{l}\text { Existem iniciativas para redução de resíduos } \\
\text { na fonte, mas raramente incorporadas em um } \\
\text { programa. }\end{array}$ & $\begin{array}{l}\text { A maior responsabilidade recai sobre a fonte e o } \\
\text { ecodesign do produto. }\end{array}$ \\
\hline & Coleta & $\begin{array}{l}\text { Em boa parte dos países, a coleta é } \\
\text { esporádica. O serviço é limitado para áreas } \\
\text { de alta visibilidade. Em geral, a coleta fica } \\
\text { abaixo de } 50 \% .\end{array}$ & $\begin{array}{l}\text { Melhores condições de coleta, há veículos } \\
\text { adequados para o trabalho e uma parte é } \\
\text { mecanizada. Em geral, a coleta cobre de 50\% } \\
\text { a } 80 \% \text { do Estado. }\end{array}$ & $\begin{array}{l}\text { Taxa de coleta superior a 90\%. Caminhões } \\
\text { compactadores e altamente mecanizados. }\end{array}$ \\
\hline & Reciclagem & $\begin{array}{l}\text { Embora a maior parte da reciclagem } \\
\text { seja feita pelo setor informal, as taxas de } \\
\text { reciclagem tendem a ser altas, tanto para } \\
\text { mercados locais como para mercados } \\
\text { internacionais. }\end{array}$ & $\begin{array}{l}\text { Setor informal ainda se mantém envolvido; } \\
\text { em alguns lugares, observa-se um } \\
\text { processamento com alta tecnologia. As taxas } \\
\text { de reciclagem são relativamente altas. }\end{array}$ & $\begin{array}{l}\text { Serviços de coleta e classificação de materiais são } \\
\text { feitos com alta tecnologia, as instalações são comuns } \\
\text { e regulamentadas. Reciclagem informal ainda existe } \\
\text { (por exemplo, coleta de lata de alumínio). }\end{array}$ \\
\hline 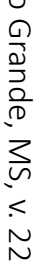 & Compostagem & $\begin{array}{l}\text { Pouco realizada formalmente, embora a } \\
\text { maior parte dos resíduos produzidos seja } \\
\text { de material orgânico. }\end{array}$ & $\begin{array}{l}\text { Existem grandes usinas de compostagem, } \\
\text { porém ainda não fazem sucesso, devido à } \\
\text { contaminação e aos custos operacionais } \\
\text { (pouca separação de resíduos). }\end{array}$ & $\begin{array}{l}\text { É um projeto popular, em quintais residenciais e } \\
\text { em instalações de grande escala. A produção de } \\
\text { resíduos tem uma porção menor de materiais } \\
\text { orgânicos do que países de baixa e média renda. A } \\
\text { separação dos resíduos no momento da coleta torna } \\
\text { a compostagem mais fácil. }\end{array}$ \\
\hline 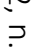 & Atividade & Baixa renda (Low Income) & Renda mediana (Middle Income) & Renda alta (High Income) \\
\hline $\begin{array}{l}\omega \\
\dot{0} \\
\infty \\
\infty \\
\infty \\
w \\
\dot{b} \\
0\end{array}$ & Incineração & $\begin{array}{l}\text { Não é comum e, quando ocorre, } \\
\text { geralmente não é bem-sucedida por causa } \\
\text { do alto custo, técnico e operacional. }\end{array}$ & $\begin{array}{l}\text { Os governos incluem a incineração como } \\
\text { possível opção de eliminação de resíduos, } \\
\text { mas os custos são altos. Pouco ou nenhum } \\
\text { monitoramento de emissões de gases. }\end{array}$ & $\begin{array}{l}\text { Prevalente em países com baixa disponibilidade de } \\
\text { espaços (por exemplo, ilhas). O custo para manter } \\
\text { um incinerador é cerca de três vezes maior que o } \\
\text { para um aterro. }\end{array}$ \\
\hline 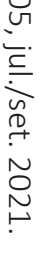 & Aterro sanitário & $\begin{array}{l}\text { Local com pouco manejo sanitário e } \\
\text { controle, normalmente aberto, onde é } \\
\text { depositada toda a geração de resíduos } \\
\text { sólidos. É altamente poluente do solo, ar e } \\
\text { água, além de impactar negativamente a } \\
\text { saúde dos moradores locais. } \\
\end{array}$ & $\begin{array}{l}\text { Presença de mais aterros sanitários } \\
\text { controlados. Também é comum a presença } \\
\text { de ferros-velhos "dumping", onde parte dos } \\
\text { resíduos fica armazenada até a venda, por } \\
\text { preços bem abaixo do mercado. }\end{array}$ & $\begin{array}{l}\text { Aterros sanitários com uma combinação de forros, } \\
\text { detecção de vazamentos, sistemas de coleta para o } \\
\text { chorume e gás. Muitas vezes, é problemático abrir } \\
\text { novas aterros devido a preocupações com moradores } \\
\text { vizinhos. Após o encerramento do uso, o espaço } \\
\text { fisico é destinado a parques. }\end{array}$ \\
\hline & Custos & $\begin{array}{l}\text { Os custos de coleta representam } 80 \% \text { a } \\
90 \% \text { das despesas com gestão municipal } \\
\text { de resíduos sólidos. }\end{array}$ & $\begin{array}{l}\text { Custos de coleta representam } 50 \% \text { a } 80 \% \text { das } \\
\text { despesas com a gestão municipal de resíduos } \\
\text { sólidos. }\end{array}$ & $\begin{array}{l}\text { Os custos de coleta podem representar menos de } \\
10 \% \text { do orçamento municipal. }\end{array}$ \\
\hline
\end{tabular}

Fonte: Informações retiradas do relatório emitido por World Bank Group (YAO et al., 2018) ${ }^{6}$.

\footnotetext{
${ }^{6}$ Ver Material Complementar A.
} 
Países da Oceania usam a reciclagem também como o principal método de destinação final dos resíduos sólidos, aproximadamente $60 \%$ dos resíduos gerados são reciclados, segundo Pickin e Randell (2016), no documento oficial do departamento de desenvolvimento e energia: Australian National Waste Report. O governo australiano elaborou metodologias para encerrar o uso de lixões e incorporou a coleta seletiva à educação ambiental nas escolas australianas. Ademais, está introduzindo a economia circular, com consecutivas reduções da geração de resíduos (PICKIN, J.; RANDELL, 2016).

O Brasil e a Indonésia possuem atualmente os maiores depósitos de lixo a céu aberto. 0 lixão da Estrutural, em Brasília, Brasil, considerado o maior da América Latina e o segundo maior do mundo, foi fechado em 2018, dando lugar a um aterro sanitário. O maior lixão localiza-se em Jacarta, capital da Indonésia, na Ilha de Java (INTERNATIONAL SOLID WASTE ASSOCIATION [ISWA], 2014), que recebe lixo de várias partes do planeta, por fazer parte de uma rede que vende plástico para a China.

Os lixões são áreas de disposição final de resíduos a céu aberto, sem planejamento ou medida alguma de proteção ao meio ambiente e à saúde pública. Em locais como esse, resíduos ainda aproveitáveis perdem grande parte do seu valor e passam à condição de lixo (LIMA, 2001; CALDERONI, 2003).

Nos continentes africano, asiático e latino-americano, encontra-se um deficit no sistema regular de coleta de lixo e uma carência de políticas públicas de saneamento básico (NASCIMENTO; CRUZ, 2017).

No continente africano, a coleta de resíduos sólidos varia de $20 \%$ a $80 \%$, dependendo do país e do município. Os resíduos são descarregados regularmente em ambientes a céu aberto, sobre o solo (lixões), sem o devido preparo do local, nem aspectos operacionais. Nesse continente, existem poucos sistemas formais de reciclagem (MARCHI, 2011).

$\mathrm{Na}$ Ásia, os fatores que afetam o gerenciamento apropriado dos resíduos sólidos são: as limitadas práticas dos órgãos públicos, a carência da legislação, os baixos recursos financeiros, a insegurança política e a deficiência na prestação de serviços. Isso produz diversos impactos ambientais, como a contaminação devido a resíduos descartados a céu aberto. Segundo a legislação, apenas devem ser separados os resíduos sólidos urbanos em "perigosos" e "não perigosos", sem ulteriores detalhamentos (GOULART et al., 2011; FIGUEIREDO, 2012).

Os governos da América Latina e do Caribe enfrentam uma série de dificuldades na gestão de resíduos, as quais agravam o problema da sustentabilidade econômica, ambiental e social dos serviços (ESPINOZA et al., 2011). Um terço do lixo produzido nos países da América Latina e no Caribe (145 mil toneladas de resíduos) é descartado diariamente em ambientes inapropriados - segundo relatório do setor de Meio Ambiente da Organização das Nações Unidas [ONU] (2018). Além disso, por estimativa, a geração diária de resíduos sólidos urbanos nesses países vai aumentar em 25\% até 2050 (ONU, 2018).

Na região latino-americana, alguns setores trabalham com economia circular. Há esforços de legislação e existem iniciativas no setor privado. Mas somente $10 \%$ dos resíduos são reaproveitados por meio da reciclagem ou outras metodologias de recuperação de materiais. Sem a aplicação de práticas mais avançadas para valorização e recuperação dos materiais descartados e de regras de governança, a carência de recursos para investimentos e custeamento das operações é, em grande parte, a causa dos problemas ambientais ocorridos no continente, com impactos diretos na saúde das pessoas (ROSA, 2018). 


\section{GERENCIAMENTO DOS RESÍDUOS SÓLIDOS}

Mesmo com o avanço nas discussões sobre a valorização do meio ambiente, o Brasil apresenta, na maior parte de seu território, descarte incorreto de lixo, coleta seletiva informal, insuficiência no sistema de coleta pública e a alta produção de lixo em ambientes urbanos. Dados da Associação Brasileira de Empresas de Limpeza Pública e Resíduos Especiais (ABRELPE, 2017) mostram que 48\% dos municípios possuem aterros sanitários, com gastos de coleta de resíduos que ultrapassam R\$ 15 bilhões anuais. Estima-se que, para a adequação das demais cidades às exigências mínimas da Lei 12.305/10, seria necessário um investimento de $\mathrm{R} \$ 11$ bilhões nos próximos anos.

Os lixões a céu aberto são os locais que recebem mais da metade dos resíduos sólidos gerados pelas cidades brasileiras que possuem pouca ou nenhuma adequação de cuidados ambientais. Essas práticas são incoerentes com a multiplicação de avanços tecnológicos, e com o apelo ao tão almejado desenvolvimento sustentável.

Entre os maiores destinos de resíduos gerados pelos municípios brasileiros, encontram-se os aterros sanitários, que, apesar de minimizarem os impactos ambientais e serem preferíveis à ausência total de tratamento, não fazem parte dos métodos mais eficientes. Entretanto a economia circular e a logística reversa, comprovadamente eficientes, estão previstas em um recente plano de lei (n. 12.305) de Política Nacional de Resíduos Sólidos (PNRS).

O Brasil vem refletindo sobre a sua forma de gerir os resíduos sólidos, pois esses compõem uma das camadas socioambientais mais sérias da atualidade e estão em relação direta com os indivíduos que os geram, independentemente do ambiente ou da condição de vida da população (ALENCAR; ROCHA; SILVA, 2015). O descarte incorreto cria impactos indesejados.

Dados do Panorama dos Resíduos Sólidos no Brasil (2017), elaborado pela ABRELPE, mostram que a geração total de resíduos sólidos urbanos foi de 78,4 milhões de toneladas em 2017, aumentando 1\% em relação a 2016. Dessa forma, cada brasileiro produziu 378 quilos de resíduos em 2017.

Comparando os dados do Panorama dos Resíduos Sólidos (ABRELPE, 2017) com os dados apresentados por Rosa (2018), a quantidade de material destinada para lixões no Brasil é igual a $25 \%$ do resíduo com destinação incorreta de toda a América Latina e o Caribe.

No Brasil, o setor de saneamento básico é insatisfatório, divergente e expõe os grandes contrastes regionais, principalmente acerca da gestão de resíduos sólidos, estabelecendo um enorme desafio para os gestores municipais (MENDEZ, 2017).

\subsection{Custos para a gestão de resíduos sólidos}

O Brasil é um país de tamanho continental, sozinho ocupa 47\% do território da América do Sul, com aproximadamente 8,5 milhões de quilômetros quadrados. Sua população é estimada em 209.188.463 habitantes (IBGE, 2019). É a sexta nação mais populosa do planeta, com 2,8\% do total mundial de habitantes (WORLDOMETERS, 2018), portanto apresenta diversos cenários para custos com gestão de resíduos sólidos.

O órgão que fiscaliza os gastos com gestão de resíduos sólidos é o Tribunal de Contas do Estado de Mato Grosso do Sul (MATO GROSSO DO SUL, 2016); para comparação e padronização, os custos são classificados em faixas demográficas:

Grupo 1 - pequeno porte: municípios com população de até 10 mil habitantes;

Grupo 2 - médio porte: municípios com população entre 10 mil e 55 mil habitantes;

Grupo 3 - grande porte: municípios com população acima de 55 mil habitantes. 
As faixas demográficas de maior população dentro dos grupos 2 e 3 (Figura 3) apresentam menores custos operacionais com os serviços de resíduos sólidos domiciliares, o que pode ser explicado pelos conceitos da economia de escala (MATO GROSSO DO SUL, 2016). A economia de escala é o princípio da diminuição do custo médio com o aumento dos serviços (CAETANO, 2014).

Figura 3 - Valores de referência de custos compreendendo: coleta e transporte de resíduos sólidos domiciliares (RSD); coleta, transporte e destinação final de resíduos de serviço de saúde (RSS) e limpeza urbana

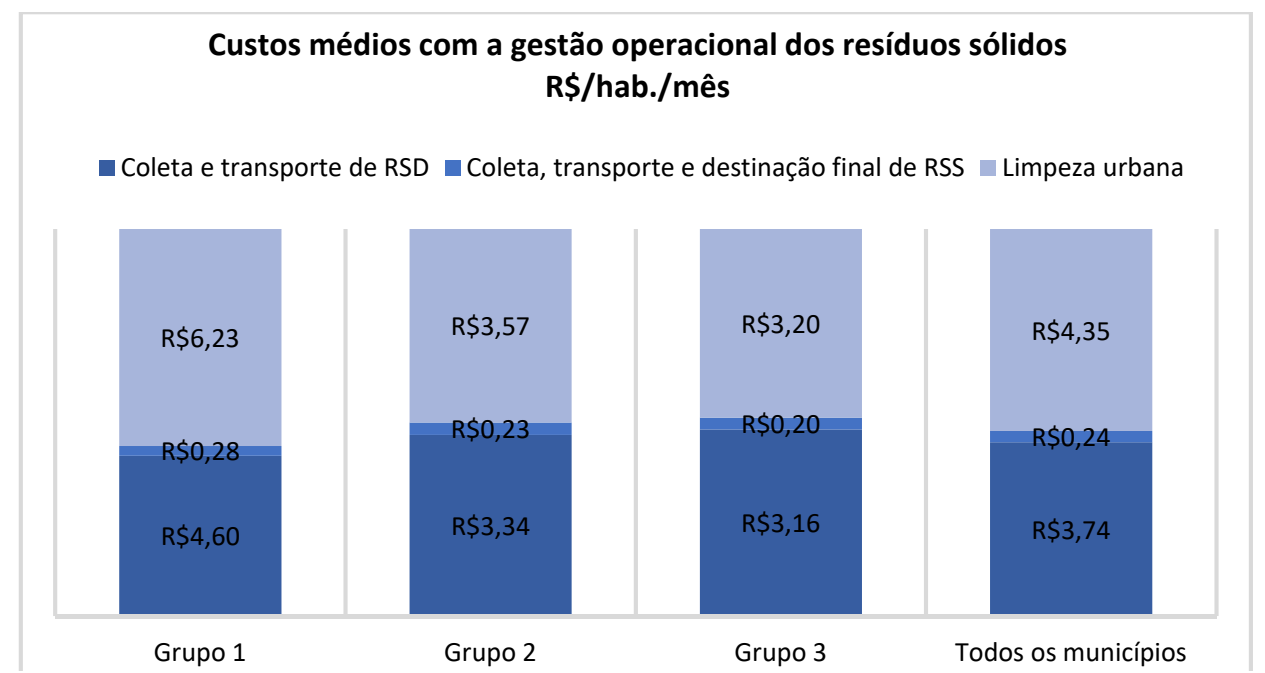

Fonte: Adaptado de Tribunal de Contas do Estado de Mato Grosso do Sul (MATO GROSSO DO SUL, 2016).

Os estados brasileiros que apresentam melhor gerenciamento para disposiç ão final dos resíduos sólidos são Santa Catarina e o Rio Grande do Sul, enquanto o Distrito Federal e o Estado de Alagoas possuem os piores dados. Já o Estado de Mato Grosso do Sul apresenta-se na média (Figura 4), de acordo com dados da ABRELPE (2016).

Figura 4 - Percentual estadual de disposição final adequada de resíduos sólidos urbanos no Brasil, 2016

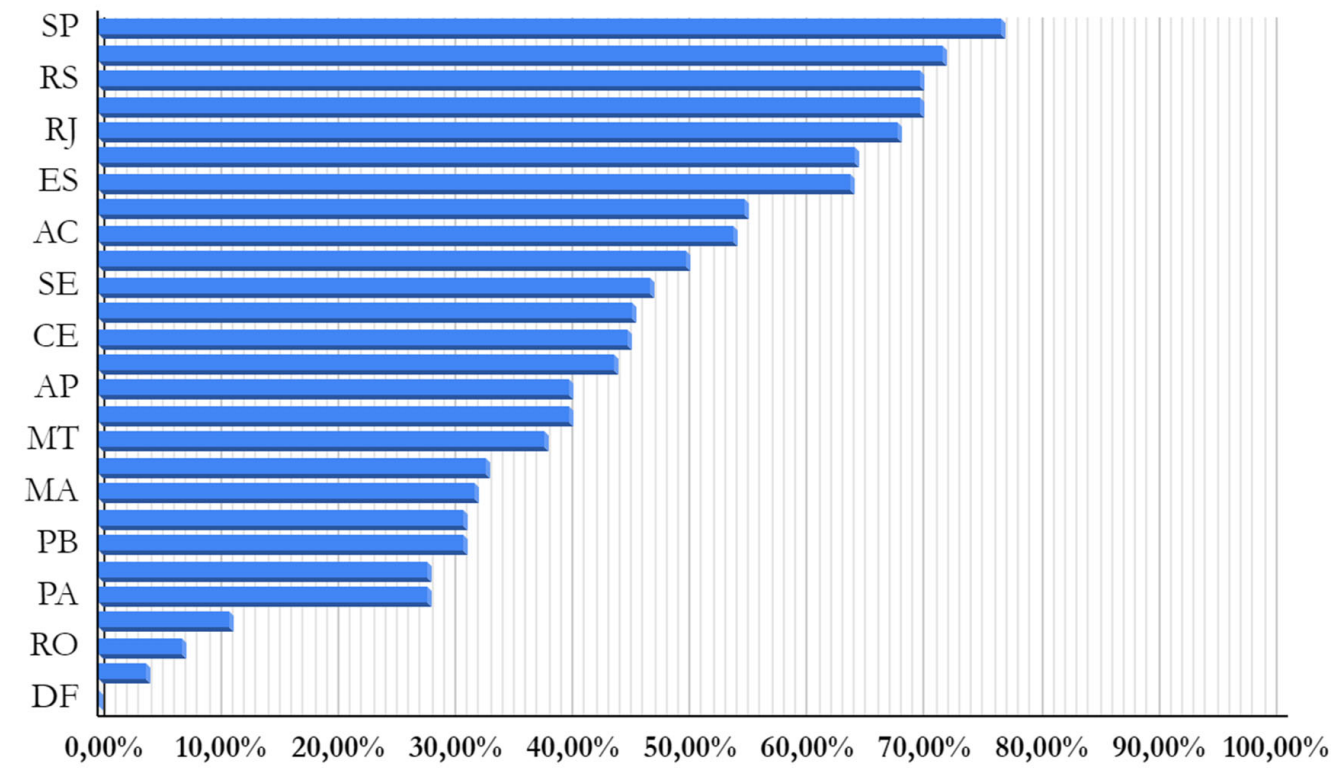

Fonte: ABRELPE (2016). 


\subsection{Resíduos sólidos no município de Bonito, Brasil}

A partir de um levantamento de dados produzidos pelo Tribunal de Contas do Estado, é possível conhecer o cenário atual da gestão dos resíduos sólidos e observam-se sensíveis desproporções, principalmente quando comparados o porte do município e a demanda de serviço (TRIBUNAL DE CONTAS DO ESTADO DE MATO GROSSO DO SUL, 2016).

Sobre o tratamento e a disposição final de resíduos sólidos, é prevista na legislação a construção de aterros sanitários, porém observa-se que a maioria dos municípios sul-mato-grossenses apresenta poucas possibilidades de investimento para construção, ou implementam aterros sanitários com baixa capacidade e curto prazo de vida útil (TRIBUNAL DE CONTAS DO ESTADO DE MATO GROSSO DO SUL, 2016).

A Política Municipal de Resíduos Sólidos do Município de Bonito foi instituída pela Lei n. 1.390 (BONITO-MS, 2015), dispondo sobre seus princípios, objetivos e instrumentos, bem como as diretrizes relativas à gestão integrada e ao gerenciamento de resíduos sólidos, incluindo os perigosos, às responsabilidades de seus geradores e do poder público e aos instrumentos econômicos aplicáveis.

A legislação municipal de Bonito, Lei n. 1.390 (BONITO, 2015), tem por princípio a visão sistêmica para a gestão dos resíduos sólidos, consideradas as variáveis: ambiente, sociedade, economia cultural, tecnologia e saúde pública. E ressalta a importância da cooperação entre as diferentes esferas de ação, envolvendo o poder público, o setor empresarial e demais segmentos da sociedade.

Segundo o Tribunal de Contas do Estado (MATO GROSSO DO SUL, 2016), os resíduos sólidos gerados no município de Bonito são destinados ao "lixão" local. De acordo com informações da Prefeitura Municipal de Bonito, o fechamento completo do lixão municipal está condicionado à abertura do Aterro Sanitário de Jardim, que se encontra em fase de finalização das obras estruturais e de obtenção de licenciamento ambiental por parte do Instituto de Meio Ambiente de Mato Grosso do Sul (IMASUL).

A cidade de Bonito, conhecida mundialmente como a Capital do Ecoturismo, busca o caminho para a sustentabilidade, expandindo o sistema de coleta seletiva e reciclagem de resíduos. O serviço já é executado no município há seis anos, mas em menor escala, e a finalidade é aumentar os investimentos no setor e permitir as conhecidas parcerias público-privadas (PPPs) para reduzir a quantidade de resíduos sólidos conduzidos ao aterro sanitário; uma vez que a unidade de Bonito está em fase de encerramento, todo o resíduo que não puder ser reciclado deve ser direcionado para o aterro de Jardim (PELLIN, 2017).

Os serviços de coleta, transporte e disposição final dos resíduos produzidos no município de Bonito, sobretudo na área urbana, são uma ação orquestrada pela prefeitura e executada por empresas terceirizadas, cujo custo final é de R\$ 4,83/hab./mês (MATO GROSSO DO SUL, 2016).

O plano municipal de gestão integrada de resíduos sólidos é elaborado junto ao Consórcio Intermunicipal para Desenvolvimento Integrado das Bacias do Rio Miranda e Apa (CIDEMA) e segue as diretrizes do Plano Intermunicipal de Gestão Integrada de Resíduos Sólidos (PIGIRS). É prevista, no plano municipal, a atuação participativa de empresar locais que contribuam com a logística reversa. 


\section{ALTERNATIVAS DE MITIGAÇÃO}

\subsection{Logística reversa}

Logística reversa é toda atividade de coletar, desmontar e processar produtos e/ou materiais e peças usadas a fim de assegurar uma recuperação sustentável, ou seja, todas as operações relacionadas à reutilização de produtos e materiais (DAHER; SILVA; FONSECA, 2006). Ela age controlando a movimentação das informações do retorno do material de pós-venda e de pós-consumo ao circuito de negócios ou à sequência produtiva, mediante canais de distribuição reversos, acrescentando-Ihes valores de diversas naturezas: econômico, ecológico, legal, logístico, de imagem corporativa, entre outros (RESENDE, 2004).

Na visão do mercado de trabalho, essa atividade é uma das melhores oportunidades para as empresas, uma vez que a maior parte delas negligencia sua cadeia de suprimentos de fluxo reverso. Uma mudança de atitude pode ainda melhorar em muito a satisfação e fidelização dos clientes (SILVA; MORAES; MACHADO, 2015).

\subsection{Reciclagem}

A reciclagem reduz o impacto sobre o meio ambiente: minimiza a extração de materiais da natureza, propicia economia de água e energia e reduz a disposição inapropriada dos resíduos. Além disso, é uma fonte de emprego para os catadores. Ela é definida pelo processo de transformação de resíduos sólidos que implica na alteração de características físicas, físico-químicas ou biológicas, com o objetivo de reaproveitar materiais em insumos ou novos produtos (BRASIL, 2010). Possibilita a substituição de insumos em um contexto de economia circular, podendo proceder em uma forte redução de emissões, relacionadas ao consumo de energia do setor industrial, suavizando as pressões de demanda por matérias-primas e por energia. Essa prática deve ser estimulada e incentivada ao mais alto nível, desde residencial até industrialmente, uma vez que produtos podem ser reutilizados, renovados ou utilizados como matéria-prima para outras indústrias (SEIBERT, 2014; GOUVEIA, 2012).

\subsection{Catadores}

Os catadores de materiais recicláveis são grandes intérpretes da indústria de reciclagem no país. Eles ocupam uma posição indispensável na gestão de resíduos sólidos no Brasil, à medida que sua própria existência mostra a complicação do sistema, dependente das práticas de catação, devido especialmente a problemas de escala de produção e a dificuldades logísticas (DIAS, 2009). Essa categoria de trabalhadores vem exercendo sua atividade de modo informal ou organizada em cooperativas. Mesmo antes da criação de políticas públicas precisas para o gerenciamento de resíduos no país, vem desempenhando um trabalho de suma relevância ambiental, colaborando consideravelmente para o retorno de diversos materiais para a série produtiva, promovendo economia de energia e de matéria-prima e impedindo que diversos materiais fiquem destinados a aterros (PEREIRA; OLIVEIRA; REIS, 1999). 


\subsection{Compostagem}

Segundo o Ministério do Meio Ambiente (BRASIL, 2017), o processo de decomposição controlada de resíduos orgânicos sob circunstâncias aeróbicas, isto é, com a presença de oxigênio, é denominado compostagem. Neste procedimento, busca-se disponibilizar um ambiente ideal (umidade, oxigênio e nutrientes) para beneficiar e agilizar a decomposição dos resíduos de forma segura (impedindo a propensão de vetores de enfermidades e eliminando patógenos). Parte-se do princípio de que uma maior diversidade de macro e microrganismos atue sucessiva ou juntamente para a decomposição acelerada dos resíduos, obtendo como produto um material de cor e textura homogêneas, com propriedades de solo e húmus, denominada composto ou adubo orgânico.

É uma metodologia simples, segura, que garante um produto uniforme, pronto para ser aplicado nos cultivos de plantas e capaz de ser realizado tanto em pequena proporção (doméstica) quanto média (comunitária, institucional) ou grande escala (municipal, industrial). Todavia é uma metodologia que precisa ser bem compreendida e bem operada para impedir complicações, como a geração de odores e a proliferação de vetores de doenças (BRASIL, 2017). Além da compostagem, existem diversos métodos para o tratamento e a destinação adequada dos resíduos orgânicos, tais como: vermicompostagem, enterramento, biodigestão e incineração. Cada método possui custos e especificidades e é preciso avaliar quais se adequam melhor a cada tratamento.

\section{ABORDAGEM LOCAL}

\subsection{Caracterização das classes/categorias}

O corpus da pesquisa "Gerenciamento de Resíduos Sólidos no município de Bonito" é a transcrição resultante das perguntas a) "O que você entende por resíduos sólidos?" b) "O que você entende por lixo?". Foram observadas 2.052 ocorrências de palavras, sendo 318 formas distintas, com frequência média de três palavras para cada forma. Esse material foi dividido em 164 unidades elementares de contexto e 7,99 ocorrências, ou seja, 51,57\% do total de palavras foi correspondidas por meio de classificações hierárquicas descendentes de segmentos de texto de tamanhos diferentes, indicando o grau de semelhança no vocabulário do tema resultante.

Na figura 5, a seguir, é possível visualizar o dendograma, que mostra as classes/categorias advindas das partições do conteúdo. 
Figura 5 - Dendograma da Classificação Hierárquica Descendente com as partições e o conteúdo corpus da pesquisa "Gerenciamento de Resíduos Sólidos no município de Bonito, Mato Grosso do Sul - Brasil", em 2019

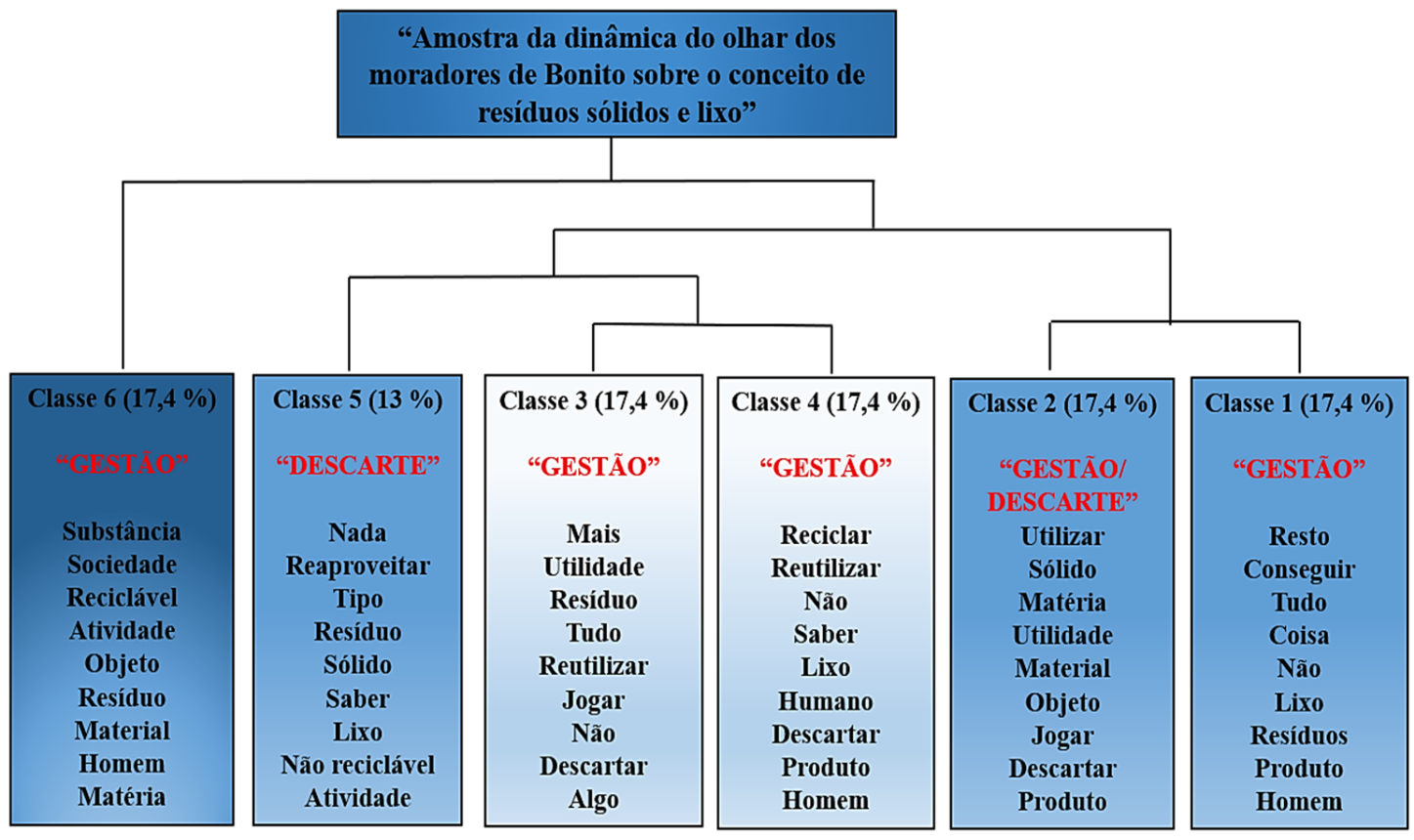

Fonte: Elaborado pelos autores.

No corpo do texto da legislação nacional de resíduos sólidos (Lei n. 12.305/10), não aparece nenhuma ocorrência da palavra lixo, ao contrário do termo resíduo sólido, que aparece cento e setenta e três vezes. O motivo mais plausível para isso é que os dois se referem a conceitos diferentes. Por lixo, entendemos algo que não tem recuperação ou qualquer serventia, e resíduo sólido percebemos como a sobra de material resultante de alguma atividade e que pode ser usada como matéria-prima (HOUAISS et al., 2009).

Mesmo que ainda se usem os termos "lixo" e "resíduos sólidos" como sinônimos, entender a diferença entre eles é uma etapa do amadurecimento e dos hábitos em relação aos cuidados com a gestão de resíduos sólidos. Observa-se que, nas categorizações do dendrograma, é possível fazer uma análise interpretativa dos grupos de palavras para os quais apresentam semelhanças com "gestão" de resíduos e aqueles que possuem semelhança com "descarte".

\subsection{Análise de similitudes}

A análise de similitudes ancora-se na teoria dos grafos, proporcionando a identificação das ocorrências entre as palavras e seu resultado nas indicações da conectividade entre elas, auxiliando na identificação da estrutura da representação (MARCHAND; RATINAUD, 2012). A partir da representação gráfica da Figura 6, observa-se que ocorreu um leque semântico de palavras mais frequentes: descartar, não, reutilizar, reciclar e material.

Após análise genérica da árvore de similitudes, pode-se considerar, por meio das conexões, que "Itens e dejetos que não podem ser reutilizados" (voluntário 7), "O que é descartado e ainda pode ser reaproveitado/reciclado" (voluntário 8) e "O que não pode ser reaproveitado" (voluntário 19). E estes entendimentos advêm de experiência de vida e conhecimentos sobre o 
tema abordado. Também, observam-se muitas dúvidas e incertezas sobre o gerenciamento de resíduos sólidos domiciliares, que podem ser confirmadas pelos vocábulos: "não; tudo e coisa", que aparecem, respectivamente, 97, 54 e 17 vezes no corpus da transcrição.

Segundo El-Deir (2014), é necessário empregar maiores investimentos na educação ambiental, em todas as classes sociais, para alcançar bons resultados na redução da produção, reciclagem e reutilização dos resíduos. Isto coincide com a expressão "Tudo o que pode ser separado no final de nosso consumo para reaproveitamento, reciclagem ou reutilização” (voluntário 23), que explicita uma intenção de gerenciar corretamente os resíduos gerados.

Figura 6 - Análise de Similitude entre as palavras - "Gerenciamento de Resíduos Sólidos em Bonito-MS", 2019

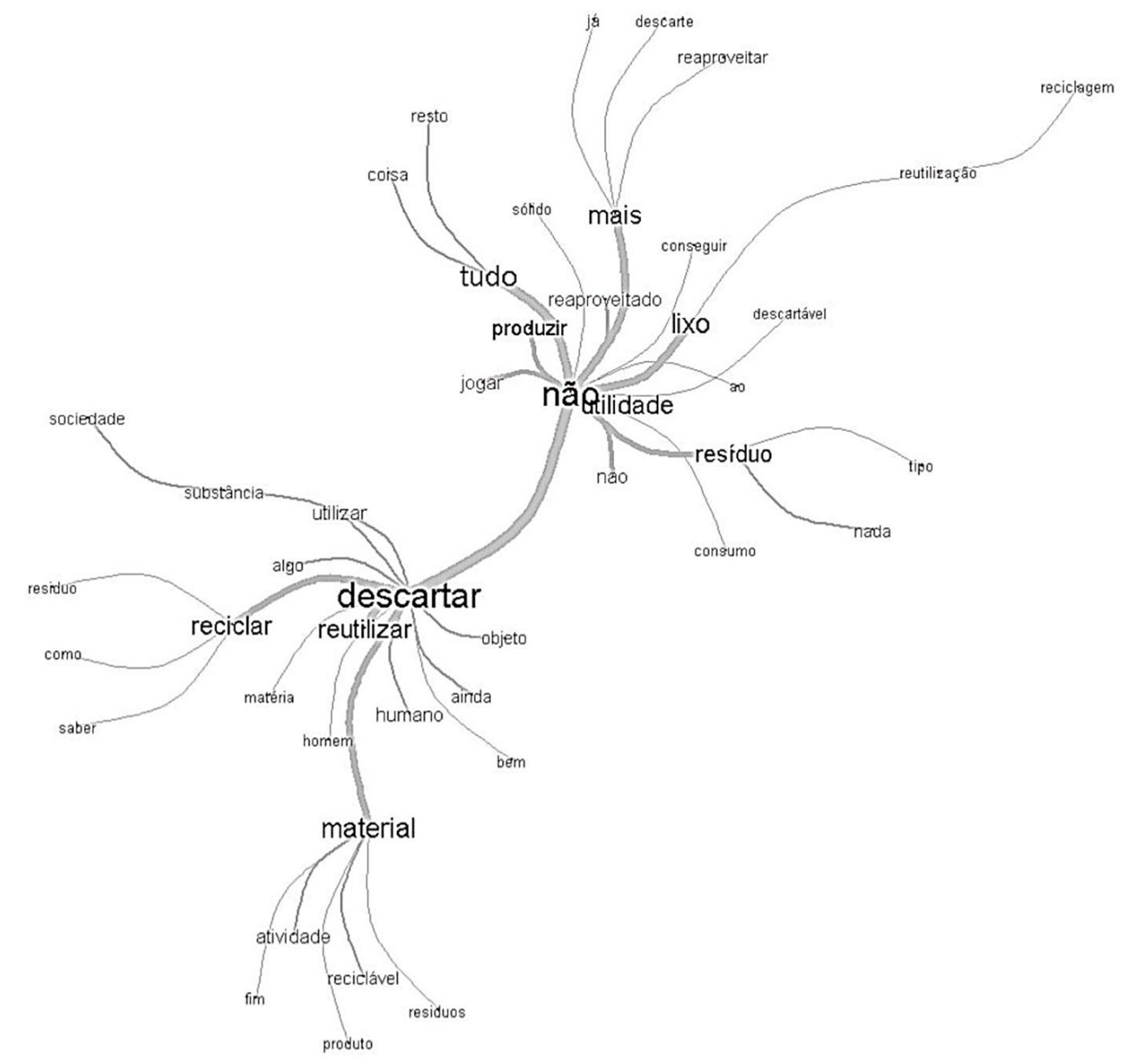

Fonte: Elaborado pelos autores.

\subsection{Nuvem de palavras}

No uso do método da nuvem de palavras, ocorre também o agrupamento e a organização gráfica das palavras em função da sua frequência, possibilitando rápida identificação das palavras-chave do corpus textual e análise lexical simples (MOURA et al., 2014). As palavras que obtiveram frequência relativa foram: "não, tudo, descartar, mais, lixo e material, que constaram 97, 54, 47, 44, 44 e 44 vezes na transcrição do corpus textual" (Figura 7). 
Figura 7 - Nuvem de palavras: "Gerenciamento de Resíduos

Sólidos em Bonito-MS", 2019

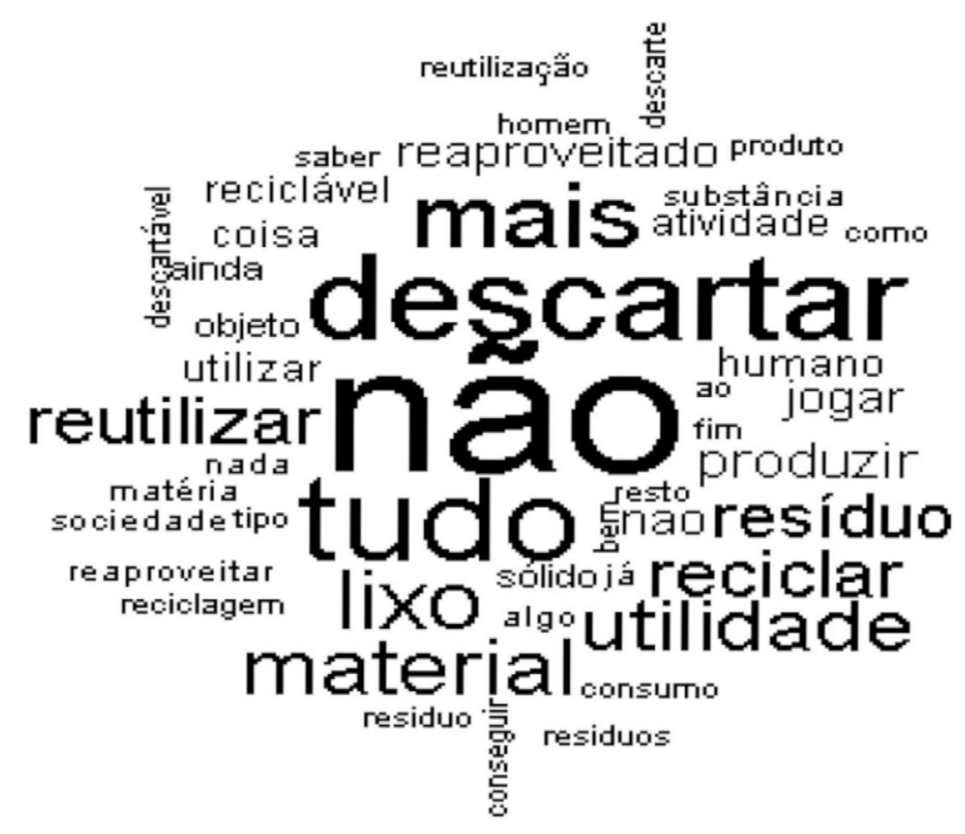

Fonte: Elaborado pelos autores.

Em relação ao termo e à definição de "resíduos sólidos", conforme o Dictionary of Water and Waste Management (SMITH, 2005), englobam-se nesse tópico os resíduos comerciais, resíduos de construção e demolição, resíduos domésticos, resíduos de jardim, resíduos industriais, entre outros, o que corresponde aos relatos "Algo que é descartado quando atinge sua inutilidade" (voluntário 25) e "Material descartado que não tem mais utilidade" (voluntário 29), que foram comprovados pelas palavras "descartar e resíduos" e corroboram com Pichtel (2005), que afirma que o resíduo sólido pode ser definido como um material sólido com valores econômicos negativos. Por outro, não se aproveitam oportunidades imensas de geração de riqueza e renda por meio da reutilização e da reciclagem (EL-DEIR, 2014).

Reutilizar um produto é utilizar mais de uma vez os materiais que são considerados inúteis, contribuindo na redução do volume de descarte, de energia e em uma nova produção de produtos (PICHTEL, 2005). Comprova-se que essa definição coincide com o relato de um dos entrevistados: "Materiais provenientes do nosso padrão de consumo que são passíveis de reaproveitar/reutilizar para outros fins, bem como reciclar com o objetivo de geração de renda ou redução" (voluntário 30).

\subsection{Caracterização dos entrevistados}

Os dados obtidos estão dispostos na Tabela 1. Os voluntários possuem idades compreendidas entre 15 e 50 anos, com uma maior incidência entre 21 e 30 anos. A escolaridade é diversificada, variando entre ensino fundamental incompleto (3\%), fundamental completo (9\%), médio completo (66\%) e ensino superior completo (22\%). No que se refere à renda, observamos que houve uma variação entre dependentes financeiros (32\%), até dois salários-mínimos (46\%), de dois a quatro salários-mínimos (14\%), de quatro a dez salários mínimos (7\%) e acima de dez (1\%). 
Quanto à destinação, a maioria das pessoas (72\%) destina para a coleta pública comum e 26\% para a coleta seletiva, sendo que a maior parte (53\%) dos voluntários realiza a separação. No entanto, segundo Bringhenti e Günther (2011), ainda se carece de informação e divulgação dos programas/iniciativas implantados, no que se refere às diretrizes, princípios, instrumentos, práticas e modalidades de coleta adotadas.

Tabela 1 - Caracterização da amostra relativa, características de gerenciamentos dos resíduos, conhecimento dos serviços oferecidos pela prefeitura e frequência percentual (F\%) da amostra no município de Bonito, Mato Grosso do Sul - Brasil, em 2019

\begin{tabular}{ccc}
\hline Amostra relativa & Características de gerenciamento & Frequência (\%) \\
\hline $\begin{array}{c}\text { Hábitos sobre a segregação de } \\
\text { resíduos domésticos }\end{array}$ & Procura separar o lixo & 53 \\
& Não há separação & 42 \\
& Não sabe & 5 \\
\hline \multirow{2}{*}{ Destinação do lixo } & Lixão & 72 \\
& Reciclagem & 26 \\
& Queima & 1 \\
\multirow{2}{*}{$\begin{array}{c}\text { Conhecimento da destinação } \\
\text { final dos resíduos? }\end{array}$} & Destino inapropriado (terreno baldio) & 1 \\
\hline \multirow{2}{*}{ O aterro deve receber todo tipo } & Sim & 59 \\
de lixo? & Não & 25 \\
& Talvez & 16 \\
\hline
\end{tabular}

Fonte: Elaborado pelos autores.

\section{CONCLUSÕES}

A preocupação com a gestão dos resíduos faz parte das agendas nacionais e internacionais e vem sendo discutida nos últimos anos, devido à expansão da consciência coletiva com relação ao meio ambiente. Observa-se que os países com maior renda disponível encontraram melhores formas de diminuir os impactos causados pelos resíduos sólidos, por meio da economia circular ou da logística reversa. Por outro lado, países com menor renda produzem mais resíduos sólidos de origem orgânica, que apresentam elevado potencial e fácil incorporação em ciclos de decomposição controlada.

A partir das análises dos grupos focais da cidade de Bonito, percebeu-se a intenção, por parte dos voluntários, de melhorar as práticas de descarte e aproveitamento. Isso se verificou nos dados coletados. Mas as análises lexicográficas do corpus textual demonstraram a negação ao ato de gerenciar, além de possíveis causas para a destinação incorreta.

No âmbito local, Bonito mostrou alguns avanços, porém a gestão dos resíduos ainda é incipiente e descoordenada, o que se repete na maior parte dos municípios brasileiros. Espera-se que, nos próximos anos, a Política Nacional de Resíduos Sólidos seja efetivamente implementada, em seus vários aspectos, na gestão dos municípios. 


\section{AGRADECIMENTOS}

O presente trabalho foi realizado com apoio da Coordenação de Aperfeiçoamento de Pessoal de Nível Superior (CAPES) - Brasil - Código de Financiamento 001.

\section{REFERÊNCIAS}

ALENCAR, T. S.; ROCHA, J. P. M.; SILVA, R. V. Política nacional de resíduos sólidos e os catadores de materiais recicláveis: estudo de caso de cooperativas nos municípios do estado do Rio de Janeiro. Revista Nacional de Gerenciamento de Cidades, Rio de Janeiro, v. 3, n. 20, p. 34-52, 2015.

ASSOCIAÇÃO BRASILEIRA DE EMPRESAS DE LIMPEZA PÚBLICA E RESÍDUOS ESPECIAIS [ABRELPE]. Panorama dos resíduos sólidos no Brasil. São Paulo: ABRELPE, 2017.

ASSOCIAÇÃO BRASILEIRA DE EMPRESAS DE LIMPEZA PÚBLICA E RESÍDUOS ESPECIAIS [ABRELPE] Panorama dos resíduos sólidos no Brasil. São Paulo: ABRELPE, 2016.

ASSOCIAÇÃO BRASILEIRA DE EMPRESAS DE LIMPEZA PÚBLICA E RESÍDUOS ESPECIAIS [ABRELPE]. Panorama dos resíduos sólidos no Brasil. São Paulo: ABRELPE, 2015.

ANDRADE, E. O.; ANDRADE, E. O. Lexical analysis of the code of medical ethics of the federal council of medicine. Revista da Associação Médica Brasileira, Manaus, v. 62, n. 2, p. 123-30, 2016.

ANDRADE, R. M.; FERREIRA, J. A. A gestão de resíduos sólidos urbanos no Brasil frente às questões da globalização. Rede: Revista Eletrônica do PRODEMA, Fortaleza, v. 6, n. 1, p. 7-22, 2011.

ARRUDA, D. O.; OLIVEIRA, G. M.; MARIANI, M. A. P. Competitividade do sistema produtivo do turismo em Bonito, MS, a partir de uma visão baseada em recursos. Interações, Campo Grande, v. 15, n. 2, p. 399-408, 2014.

BONITO (Cidade). Secretaria de meio ambiente quer a revitalização da unidade de tratamento de resíduos (UTR). Prefeitura Municipal de Bonito, MS, 8 de fevereiro de 2017. Disponível em: https://www.bonito.ms.gov.br/2017/02/08/secretaria-de-meio-ambiente-quer-a-revitalizacaoda-unidade-de-tratamento-de-residuos-utr/. Acesso em: 18 out. 2021.

BONITO (Cidade). Lei n. 1.390, de 10 de setembro de 2015. Política municipal de resíduos sólidos do município de Bonito. Bonito-MS, 2015.

BRASIL. Ministério do Meio Ambiente [MMA]. Compostagem doméstica, comunitária e institucional de resíduos orgânicos. Brasília-DF: MMA, 2017.

BRASIL. Lei Federal n. 12.305/2010, de 2 de agosto de 2010. Institui a Política Nacional de Resíduos Sólidos; altera a Lei n. 9.605, de 12 de fevereiro de 1998; e dá outras providências. Diário Oficial de União, Brasília, 2 ago. 2010. Disponível em: http://www.planalto.gov.br/ ccivil_03/_ato20072010/2010/lei/l12305.htm.

BRINGHENTI, J. R.; GÜNTHER, W. M. R. Participação social em programas de coleta seletiva de resíduos sólidos urbanos. Engenharia Sanitária Ambiental, Cidade, v. 16, n. 4, p. 421-30, 2011. 
CAETANO, M. A. Economias de escala e escopo na previdência complementar fechada brasileira. Rio de Janeiro: IPEA, 2014. (Texto para Discussão, 1954).

CALDERONI, S. Os bilhões Perdidos no lixo. 4. ed. São Paulo: Humanitas; USP, 2003.

DAHER, C. E.; SOTA S. E. P.; FONSECA, A. P. Logística reversa: oportunidade para redução de custos através do gerenciamento da cadeia integrada de valor. BBR-Brazilian Business Review, Vitória, v. 3, n. 1, p. 58-73, 2006.

DIAS, S. L. F. G. Catadores: uma perspectiva de sua inserção no campo da indústria de reciclagem. 2009. Tese (Doutorado em Ciência Ambiental) - Universidade de São Paulo, São Paulo, SP, 2009. doi: https://www.doi.org/10.11606/T.90.2009.tde-25102010-231013

EL-DEIR, S. G. Resíduos sólidos: perspectivas e desafios para a gestão integrada. 1. ed. Recife: EDUFRPE, 2014. p. 393.

ESPINOZA, P. T.; ARCE, E. M.; DAZA, D.; FAURE, M. S.; TERRAZA, H. Relatório da avaliação regional da gestão de resíduos Sólidos urbanos na América Latina e Caribe 2010. Minas Gerais: AIDIS, 2011.

FIGUEIREDO, F. F. Similitudes na gestão dos resíduos sólidos urbanos em países centrais e periféricos. Biblio 3W: Revista Bibliográfica de Geografía y Ciencias Sociales. Barcelona, v. 17, n. 975, p. 2-8, 2012. Disponível em: https://repositorio.ufrn.br/handle/123456789/18715. Acesso em: 18/10/2021.

GOULART, A. M. R.; BREJÃO, A. S.; OLIVEIRA, R.; GOMES, S. R. F.; TEIXEIRA, E. P.; IRAZUSTA, S. P. Gerenciamento de resíduos sólidos urbanos: um panorama das regiões da Ásia e África. In: WORKSHOP DE PÓS-GRADUAÇÃO E PESQUISA DO CENTRO PAULA SOUZA [CPS], 6., 9-10 nov. 2011, São Paulo. Workshop. Anais [...]. São Paulo: CPS, 2011. p. 3-11.

GOUVEIA, N. Resíduos sólidos urbanos: impactos socioambientais e perspectiva de manejo sustentável com inclusão social. Ciência \& Saúde Coletiva, São Paulo, v. 17, n. 6, p. 1503-10, 2012.

HOUAISS, A.; VILLAR, M. S. Dicionário Houaiss da língua portuguesa. 1. ed. Rio de Janeiro: Objetiva, 2009.

IBGE. Censo demográfico brasileiro: população estimada. Rio de Janeiro: IBGE, 2018.

INTERNATIONAL SOLID WASTE ASSOCIATION [ISWA]. Waste atlas report: the world's 50 biggest dumpsites. Viena: ISWA, 2014. Disponível em: https://nswai.com/docs/World's\%20Fifty\%20 biggest\%20dumpsites,Waste\%20Atlas\%202014.pdf. Acesso em : 19 out. 2021

KAMI, M. T. M.; LAROCCA, L. M.; CHAVES, M. M. N.; LOWEN, I. M. V.; SOUZA, V. M. P.; GOTO, D. Y. N. Trabalho no consultório na rua: uso do software IRAMUTEQ no apoio à pesquisa qualitativa. Escola Anna Nery, Curitiba, v. 20, n. 3, p. 02-04, 2016.

LIMA, J. D. Gestão de resíduos sólidos urbanos no Brasil. Paraíba: Editora João Pessoa, 2001.

MANNARINO, C. F.; FERREIRA, J. A.; GANDOLLA, M. Contribuições para a evolução do gerenciamento de resíduos sólidos urbanos no Brasil com base na experiência Européia. Engenharia Sanitaria e Ambiental, Rio de Janeiro, v. 21, n. 2, p. 379-85, 2016. 
MARCHAND, P.; RATINAUD, P. L'analyse de similitude appliquée aux corpus textuels: les primaires socialistes pour l'élection présidentielle française (septembre-octobre 2011). In: JOURNÉES INTERNATIONALES D’ANALYSE STATISTIQUE DES DONNÉES TEXTUELLES, 11., 13-15 jun. 2012. Anais [...]. Toulouse: JADT, 2012. p. 687-99.

MARCHI, C. M. D. F. Cenário mundial dos resíduos sólidos e o comportamento corporativo brasileiro frente à logística reversa. Perspectivas em Gestão \& Conhecimento, Salvador, v. 1, n. 2, p. 118-35, 2011.

MATO GROSSO DO SUL (Estado). Tribunal de Contas do Estado de Mato Grosso Do Sul. Indicadores de resíduos sólidos nos municípios de MS. Campo Grande: Agilità Propaganda, 2016.

MENDEZ, G. P. Avaliação da gestão municipal de resíduos sólidos através de indicadores ambientais. 2017. 194 f. Dissertação (Mestrado em Engenharia Civil) - Universidade Federal do Rio de Janeiro, Rio de Janeiro, RJ, 2017.

MOURA, L. K. B. Revisão integrativa sobre o câncer bucal. Revista de Pesquisa Cuidado é Fundamental, Rio de Janeiro, v. 6, n. 5, p. 164-75, 2014.

NASCIMENTO, C. M. T.; CRUZ, M. L. B. Resíduos sólidos: presença e ameaça no espaço geográfico. Geotextos, Ceará, v. 13, n. 2, p. 2-24, 2017.

ORGANIZAÇÃO DAS NAÇÕES UNIDAS [ONU]. Assembleia Geral das Nações Unidas. Convenção das Nações Unidas sobre mudanças climáticas. Brasília-DF: ONU, 2018.

PELLIN, K. Bonito amplia sistema de coleta seletiva do lixo em preparativo a mudança de aterro sanitário. Portal da educativa, Bonito, 2017. Disponível em: http://www.portaldaeducativa. ms.gov.br/bonito-da-mais-um-passo-em-favor-do-meio-ambiente-e-vai-implantar-sistema-decoleta-seletiva-do-lixo. Acesso em: 25 nov. 2019.

PEREIRA, A. S.; OLIVEIRA, L. B.; REIS, M. M. Emissões de $C^{2}{ }^{2}$ evitadas e outros benefícios econômicos e ambientais trazidos pela conservação de energia decorrente da reciclagem de resíduos sólidos no Brasil. In: ENCONTRO NACIONAL DA SOCIEDADE BRASILEIRA DE ECONOMIA ECOLÓGICA, 3., 11-13 nov. 1999, Recife. Anais [...]. Recife: ECO-ECO, 1999.

PICHTEL, J. Waste management practices: municipal, hazardous, and industrial. 2. ed. Boca Raton: CRC press, 2005.

PICKIN, J.; RANDELL, P. Australian national waste report 2016. Australia: Blue Environment Pty Ltd, 2016. Disponível em: https://www.environment.gov.au/system/files/resources/d075c9bc45b3-4ac0-a8f2-6494c7d1fa0d/files/national-waste-report-2016.pdf

RESENDE, E. L. Canal de distribuição reverso na reciclagem de pneus: estudo de caso. 2004. 118 f. Dissertação (Mestrado em Engenharia Industrial) - Pontifícia Universidade Católica, Rio de Janeiro, RJ, 2004.

ROSA, R. Um terço do lixo na América Latina é descartado inadequadamente. Folhapress, São Paulo, 2018. 
SANTOS A. T.; ROCHA, J. P. M.; SILVA, R. V. Política nacional de resíduos sólidos e os catadores de materiais recicláveis: estudo de caso de cooperativas nos municípios do estado do Rio de Janeiro. Revista Nacional de Gerenciamento de Cidades, Tupã, v. 3, n. 20, p. 34-52, 2015.

SEIBERT, A. L. A importância da gestão de resíduos sólidos urbanos e a conscientização sobre sustentabilidade para a população em geral. 2014. 44 f. (Especialização em Gestão Ambiental em Municípios) - Universidade Tecnológica Federal do Paraná, Medianeira, PR, 2014.

SENADO FEDERAL. Resíduos sólidos: lixões persistem. Em Discussão! Os principais debates do Senado Federal, Brasília-DF, ano 5, n. 22, p. 12-35, set. 2014.

SILVA, A. L. E.; MORAES, J. A. R.; MACHADO, Ê. L. Proposta de produção mais limpa voltada às práticas de ecodesign e logística reversa. Engenharia Sanitária e Ambiental, Santa Cruz do Sul, v. 20, n. 1, p. 29-37, 2015.

SMITH, P. Dictionary of water and waste management. Escócia: Butterworth-heinemann, 2005. $480 \mathrm{p}$.

SOUZA, M. A. R.; WALL, M. L.; THULER, A. C. M. C.; LOWEN, I. M. V.; PERES, A. M. O uso do software IRAMUTEQ na análise de dados em pesquisas qualitativas. Revista da Escola de Enfermagem da USP, Curitiba, v. 52, n. xx, e03353, 2018.

WORLDOMETERS. Countries in the world by population in 2018. Worldometers, [s.l.], 2018. Disponível em: http://www.worldometers.info/world-population/population-by-country/. Acesso em: 19 out. 2021.

YAO, L.; WOERDEN, F.; KAZA, S.; BHADA-TATA, P. What a waste 2.0: a global snapshot of solid waste management to 2050. Washington: World Bank Group, 2018.

\section{Sobre os autores:}

Lais Ribeiro Balbueno: Pós-graduanda em Perícia e Auditoria Ambiental pelo Centro Universitário Internacional (UNINTER). Graduada em Ciências Biológicas pela Universidade Católica Dom Bosco (UCDB). E-mail: laisribeiro@gmail.com Orcid: https://orcid.org/0000-0001-8707-3197

Lorene Almeida Tiburtino-Silva: Doutora e mestre em Desenvolvimento Local pela Universidade Católica Dom Bosco (UCDB). Bolsista Capes. E-mail: lorenetiburtino@yahoo.com.br, Orcid: https://orcid.org/0000-0003-0463-7132

Micaella Lima Nogueira: Doutoranda em Ciências Ambientais e Sustentabilidade Agropecuária na Universidade Católica Dom Bosco (UCDB). Graduada em Ciências Biológicas pela UCDB. Atualmente é bolsista FUNDECT. E-mail: mican1805@gmail.com, Orcid: https://orcid.org/0000-0001-8371-2772

Josemar de Campos Maciel: Doutor em Psicologia pela Pontifícia Universidade Católica de Campinas (PUC-Campinas). Atualmente é professor titular de graduação e pós-graduação na Universidade Católica Dom Bosco (UCDB). E-mail: maciel50334@yahoo.com.br Orcid: https://orcid.org/0000-0001-8277-9422

Reginaldo Brito da Costa: Doutorado em Ciências Florestais pela Universidade Federal do Paraná (UFPR). Mestre em Ciências Florestais pela Universidade de São Paulo (USP). Graduado em 
Engenharia Florestal pela Universidade Federal de Mato Grosso (UFMT). Atualmente é professor titular de graduação e pós-graduação na Universidade Católica Dom Bosco (UCDB). E-mail: reg.brito.costa@gmail.com, Orcid: https://orcid.org/0000-0002-5677-393X 
